\title{
The importance and earnest of the researcher in pointing out the study limitations
}

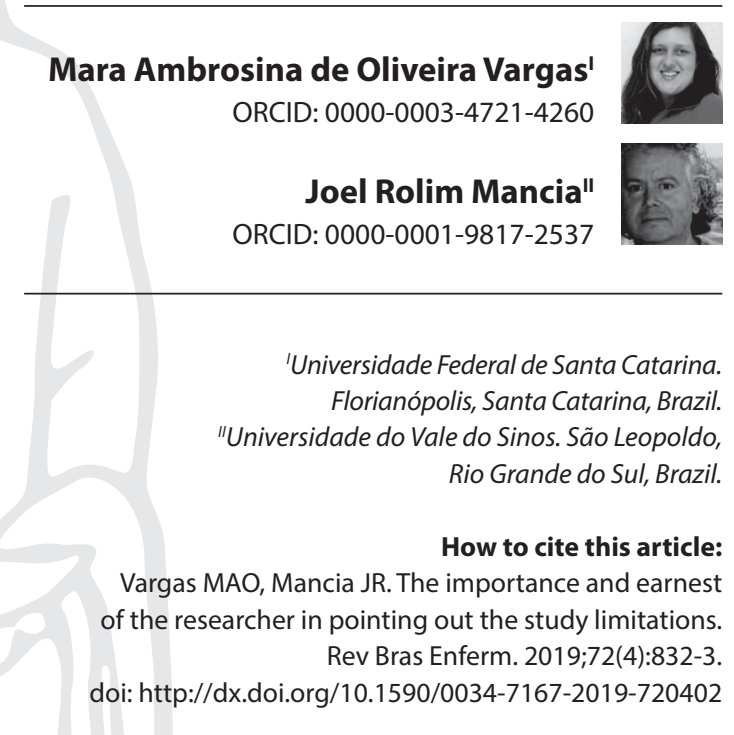

Scientific journals indexed with editorial norms and recommendations regarding the integrity and ethical standards in the conduct of the research report ${ }^{(1)}$ have pointed out to the authors of both qualitative and quantitative researches the clear explanation of the study limitations. Supposedly, no scientific work is free of limitations, so it is signaled that its description does not consist in something inherently bad. On the contrary, it is a duty of the researcher to provide the reproducibility and leveling of the path that others must follow, to show where to make greater efforts next time, or as "not to stumble over the same stone again".

However, although many scientific papers are considered of excellent quality, that is, consistent and produce relevant and original knowledge, they do not follow all established criteria. In this sense, the study limitations have been one of the less pointed aspects ${ }^{(2)}$. In turn, many who contemplate this item confuse "study limitations" with "method limitations". For example, indicating that research has limitations of generalization of qualitative studies is to describe something inherent to the specificities of the qualitative method and not to the limitations recognized by the author in his text. In some, the author comes to hold the interlocutor responsible for the scarcity of information collected ${ }^{(2)}$.

The sample size may be included among the limitations. In this sense, there are explicit differences between qualitative and quantitative research. It should be considered that with a small size it is difficult to find meaningful relations and generalizations from the data, since statistical tests require a larger sample size to guarantee a trend, a representative distribution of groups of people, objects, processes, among others ${ }^{(3)}$.

Questions that were not explained and that appeared with the development of the work could be pointed out as study limitations, but there were no reliable data or because of the lack of data could not be answered. These limitations should be described, but also provide reasons why you believe the data is missing or unreliable, which will be very useful as an opportunity to describe future research needs ${ }^{(1,3)}$.

The lack of previous research on the topic addressed can also be pointed out as a limitation of the study. But before assuming that there is little research on the subject, the main national and international databases should be widely and rigorously consulted. Identifying such a limitation can also serve as an opportunity to identify new gaps in the literature and, consequently, new investigations(2).

Data self-reported by survey participants may also contain several potential sources of bias and be listed as study limitations because they can rarely be independently verified ${ }^{(3)}$. The reasons for possible limitations of the researcher's access to people, organizations or documents should be described as well.

Yet, cultural constraints and other types of prejudice constitute a bias, insofar as a person, place or thing is viewed or displayed inaccurately. Bias is generally negative, although there may also be a positive bias, especially if this bias reflects your confidence in research that supports only your hypothesis ${ }^{(2)}$. 
Anyway, when editing your paper, you must critically edit how you've posed a problem, select the data to be studied, what you may have omitted, how you ordered the procedures, events, people, or places. But note that it is very difficult to homogenize the limitations in a way that works for all studies. Limitations can be general and also specific to each study. Every study is different. Therefore, although the limitations may determine generalities, there are specificities that will not be associated with any aspect discussed here.

\section{REFERENCES}

1. International Committee of Medical Journal Editors. Recommendations for the Conduct, Reporting, Editing, and Publication of Scholarly Work in Medical Journals[Internet]. International Committee of Medical Journal Editors. 2019[cited 2018 Oct 22]. Available from: http:// www.icmje.org/urm_main.html

2. Taqquete SR, Minayo MC. Análise de estudos qualitativos conduzidos por médicos publicados em periódicos científicos brasileiros entre 2004 e 2013. Physis Rev Saúde Colet. 2016;26(2):417-34. doi: http://dx.doi.org/10.1590/S0103-73312016000200005

3. Price JH, Murnan J. Research Limitations and the Necessity of Reporting Them. Am J Health Educ. 2004;35(2):66-7. doi: https://doi.org/10.10 80/19325037.2004.10603611 